\title{
In-Situ Domestic Load Harmonic Detection and Reduction Based on GLRM Algorithm for Optimum Filter Excerpt
}

\author{
Deepthi Joseph', N. Kalaiarasi², K. Rajan ${ }^{1}$ \\ ${ }^{1}$ Department of Electrical and Electronics Engineering, Vel Tech Engineering College, Anna University, Chennai, \\ India \\ ${ }^{2}$ Department of Electrical and Electronics, Engineering, R. M. K. C. E. T, Anna University, Chennai, India \\ Email: deepthijosephvt@gmail.com
}

Received 1 April 2016; accepted 25 April 2016; published 5 July 2016

Copyright (C) 2016 by authors and Scientific Research Publishing Inc.

This work is licensed under the Creative Commons Attribution International License (CC BY). http://creativecommons.org/licenses/by/4.0/

c) (i) Open Access

\begin{abstract}
Power Quality measures the reliable operation between the system and to the connected loads of same system. A poor power quality causes physical damage to the equipment and also results in lower productivity with increase in energy costs. Power disturbances range from micro seconds to hours and the prolonged disturbances in hours would damage the equipments. The power quality decreases due to growth of nonlinear loads in domestic appliances, such as home Uninterrupted Power Supplies (UPS), Induction stove, Television etc. Nowadays Domestic loads are controlled or powered with power electronic devices. The power electronic devices with Direct Current (DC) components generate high frequency signal for DC-Alternating Current (AC) conversion. The conversion introduces multiple frequencies in the AC power supply. The multiple frequencies in AC power supply are called as harmonics. The harmonics in AC supply affects the lifetime of home appliances, consumes more electric current, affects the power factor, transformer efficiency, and other electricity supply systems. Till now, to avoid harmonics, the filters are erected only in industrial loads or in the substations. In this paper a novel method to detect and control harmonics in domestic appliances is proposed. Harmonic control with various filters in the filter bank, based on detection of harmonic voltage let out from the domestic appliances for power saving. To select the appropriate filter to improve power quality, we apply a novel Genetic Algorithm based Linear Regression Method (GLRM) algorithm for optimum Filter Selection. From the results we were able to reduce the total harmonic distortion level to $3.68 \%$. The current consumption of each household appliance is reduced considerably and finally the electricity bill is reduced to $15 \%$ and overall system efficiency improves to $85 \%$.
\end{abstract}


Keywords

Power Quality, Domestic Appliances, Harmonic Detection, Harmonic Control, Filter,
GLRM Algorithm

\section{Introduction}

The electrical power system operates at a particular frequency called the fundamental frequency which will be $50 \mathrm{~Hz}$ or $60 \mathrm{~Hz}$. Fundamental operating frequency integers multiple forms electrical harmonics. The harmonics generate from any nonlinear loads. The nonlinear loads such as personal computers, Light Emitting Diode Tele Vision (LED TV), electronic ballasts, home UPS etc. generate more harmonics in residential areas [1]. Various domestic load generates harmonics in large, in day today life. The generated harmonics should be monitored and analysed for the current consumption of the loads. However, recent survey states that a minimum of ten electronic gadgets in use at home. These gadgets will pollute the power supply due to nonlinear characteristics. The pollution in supply forms the profile of pulses. Pulse current analysis would be difficult rather than a sine wave on power systems. The pulsed current drawn can be periodic but may be symmetric or asymmetric. In symmetrical wave positive portion of signal looks similar to the negative half, whereas vice versa for asymmetric signals. In symmetric current waveform consists of odd harmonics wherein asymmetrical waveform contains both odd and even harmonics. The symmetrical and asymmetrical current waveforms avail practically in all domestic loads. The asymmetric harmonic current generates harmonics in the voltage due to the impedance between source and load. The generated harmonic voltage cumulates along with the source voltage and ultimately voltage distortion occurs. The distortion voltage magnitude relies based on source impedance and harmonic voltages [2]. The source impedance always proportion with nonlinear loads and due hence harmonic voltage increase in power systems. The harmonic voltage and current leads to various problems in domestic appliances such as heating, equipment malfunction, failure, communication interference, process problems etc.

Harmonic distortion increases in day today life due to increase in usage of electronic gadgets in the form of nonlinear loads for long hours. Till now and then, the electronic gadgets in domestic appliances generated harmonics in the power supply considered to be negligible. Nowadays long hour usage of nonlinear electronic gadgets becomes a major source of harmonics in the supply voltage.

The problem related to injection of harmonics from the home appliances is calculated and studied in a form of survey taken from a group of apartments of more than 450 houses. From the survey we found that harmonics generated at home cannot be considered as negligible amount of harmonics since the growth of harmonic is rapid.

In this paper a novel method to suppress harmonics is implemented in household application with different filters. The selection of filters is based on continuous monitoring of harmonic data and GLRM algorithm for decision making.

The rest of the paper is organized as follows. Section 2 discusses on the related work considering the harmonic data analysis. Section 3 introduces the methodology followed in the proposed method. Section 8 discusses on results and interferences based on the proposed method. Finally Section 9 briefs the conclusion drawn from the harmonic order analysis.

\section{Related Work}

The harmonics generated from domestic loads need to be taken care for undistorted supply. Moreover, the harmonics should be filtered at the generation point so that the cumulating of harmonic effects in the supply can be reduced enormously; still many filters are designed for the harmonic reduction. The elimination of cumulative effect of harmonics from different houses tried nearer to the service transformer [3]. The harmonic reduction always done with filters. Often the researchers develop the filters to control only the troublesome harmonic voltages instead of controlling all the harmonic levels. Harmonic voltage control in industrial environment takes place only for the triple order harmonic voltages [4]. The voltage controlled harmonic filter, depends on the nature of load. The load plays a vital role for the efficient filtering along with variation in parameters [5]. The filters classify as active and passive filters. The active filters can effectively perform in controlling the harmonics 
in large distribution systems [6]. The active filters can generate sub harmonics which leads to power quality issues. However the errection of active filter in the distribution system done based on energy audit. The harmonic voltage affects all electronic gadgets and instruments. The harmonic voltage creates noise in all communication devices due to electromagnetic interference property. The electromagnetic interference in communication devices such as landline phones, walkie talkie, becomes a common problem for the human being in the areas where more harmonics are generated [7]. Harmonic voltage analysis in industrial environment is done for various distributions and loads. Harmonic voltage analysis can be utilised for the transformer fault detections [8]. Similarly for all other device's faults can also be analysed with harmonic voltage. However the harmonic injection from the domestic loads and their influences in the distortion of power supply becomes vital in the forth coming years, [9]. All the active filter designs made based on the grid point of view and various loads, not providing much importance to local mitigation of harmonics [10]. The notch filter eliminates the harmonics for only static load [11]. The harmonic analysis for large scale residential power networks based on out of sequence measurements for designing the filter plays a major role due to increase of nonlinear loads in domestic appliances [12]. The various techniques are developed for harmonic measurement. The Harmonic prediction in the point of common coupling between a transmission network and the utility network leads to a complicated modelling of phasor model [13]. The other method to measure harmonics can be based on impedance on the network as well as harmonic current measurement [14].

Till now and then the harmonic analysis is calculated for the industrial environment based on the loads present in that location. For those loads active filters are erected to reduce harmonics. Harmonic analysis and reduction is given much importance in various fields such as renewable energy, electrical transmission systems [15]. However there is a need to evaluate harmonic injection from domestic loads under different running conditions such as day, night hours, various loads such as mixer, microwave oven, electronic ballasts etc. The effect of harmonic injection from domestic load increases day by day also to be calculated. The different combination of domestic loads and their harmonic generations needs calculation. Finally keeping the above constrains, an efficient filter has to be designed and evaluated for power quality. Till now the filters, normally fixed near to the service transformer. The filter at the distribution transformer can only eliminate particular harmonic based on approximation from energy audited results. The filter at the distribution transformer perform efficiently only for industrial loads. The industrial loads running hours are predominantly known, so the harmonic calculation is easy and predictable whereas the cumulative harmonics from different houses makes the prediction of harmonic levels difficult. However, for the industrial loads the loads and the running hours are known well and whereas for domestic loads running hours for each loads varies as wells the no of loads increases [16].

Harmonic analysis and related design of filter bank is even proposed to be implemented in roll mill applications with an optimal design [17]. To select the appropriate filter for the harmonic mitigation is done based on the genetic algorithm for better accuracy [18]. Other decision making algorithms are also present such as fuzzy logic which involves algorithm of making constraint based fuzzy rules [19]. Decision making logic becomes tedious when it is involved with the data and the harmonic order as discussed earlier [20]. An FFT based algorithm is used to extract the harmonics while using a specific combination of load. Even iron losses in induction motors also can be analysed based on the harmonic data [21].

In this paper, we propose for the different combination of domestic loads and their load characteristics effect of harmonics are calculated and filtered with appropriate filters based on loads and harmonics. The next section introduces a method of analysing the harmonics due to nonlinear loads from a household and a way of mitigating them from the roots.

\section{Real Time Evaluation of Harmonic Generation in Residential Apartments}

The study of harmonic generation for the proposed method is evaluated in a residential area of about 572 houses in four blocks of Kendriya Vihar residential apartment located at Avadi, Chennai, Tamil Nadu, India. From the survey, an average of each house in the block has one inverter, two stabilizers for LED TV and refrigerator, an average of three to five chargers for laptops, one UPS system for personal computer, iPad, mobiles, laptops; routers etc. Estimation of power quality analysis made in the blocks which consists of 128 houses in each block, connected with $500 \mathrm{KVA}$ distribution transformer. The residential apartment where the harmonic monitoring conducted is shown in Figure 1. The harmonics generated from each household appliance are calculated based on the usage of each power electronic devices such as adapters, UPS etc. The harmonics generated from 128 houses is an average of Total Harmonic Distortion (THD). The statistics are shown in Table 1. 


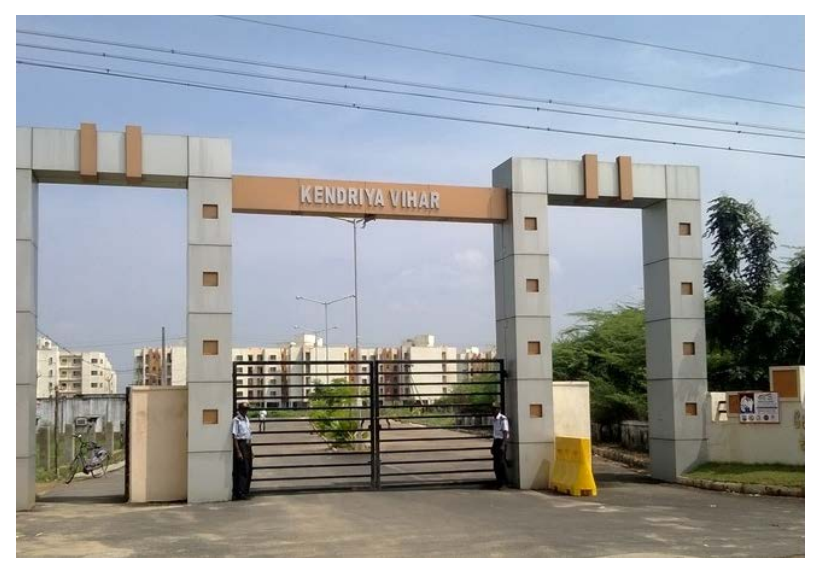

Figure 1. Residential area under consideration for harmonic analysis.

Table 1. Harmonics percentage injected by an individual home.

\begin{tabular}{cccc}
\hline Sl.no. & Appliance & Quantity & \% THDi \\
\hline 1. & Fridge & 1 & 61.8 \\
2. & LED TV & 1 & 72 \\
3. & Fan Regulator & 3 & 67.5 \\
4. & CFL & 5 & 55 \\
5. & laptop & 1 & 83 \\
& Total Current Harmonics from an average home & $340 \%$ \\
\hline
\end{tabular}

However the power quality can be controlled in the individual houses with filter banks based on the measurement of harmonic level and usage time of devices, whereas in industrial loads, active filters provides a good mitigation for harmonics due to the well defined loads, whereas for domestic loads, the harmonic separation is a challenging task due to non-defined loads. From the real time evaluation of harmonics in the apartment, we identified that the generation of harmonics in distributed individual houses is low when compared with industrial loads; the cumulative harmonic generation of houses in the apartments increases the harmonic level and affects the power supply system and also other parallel connected loads.

\section{Implementation of Harmonic Detection and Reduction}

From 128 houses connected with a 500 KVA transformer, the measured harmonic analysis shows that an average of $340 \%$ current harmonics is injected to the electric supply system from an average individual house. From the measurements, the result shows the importance of implementing a local filter in individual houses to mitigate the harmonics.

From the set of harmonic frequency data collected in real time environment from different combination of household appliances gives an idea to design various filters based on THD. To mitigate a particular order harmonic created by a specific combination of load, a suitable filter from a filter bank is selected according to the harmonic content based on GLRM algorithm. However in this paper, we propose a novel decision making algorithm for the selection of filters as shown in Figure 2. The proposed filter connected to the secondary feeder to control harmonics generated from domestic loads.

To control the harmonics in real time, the most important factor is understanding the current drawn by the nonlinear loads during individual and combined operation. After measurement of current, those currents are analysed in such a way that the predominant harmonics are identified by using a fast Fourier transform technique and a corresponding filter has been designed by using threshold values obtained from the analysis. The genetic algorithm is used for decision making in appropriate filter selection. Genetic algorithm property of constrained optimization based on natural selection of harmonic equation relating voltage and harmonic order in accordance with the dominant harmonic order present. 


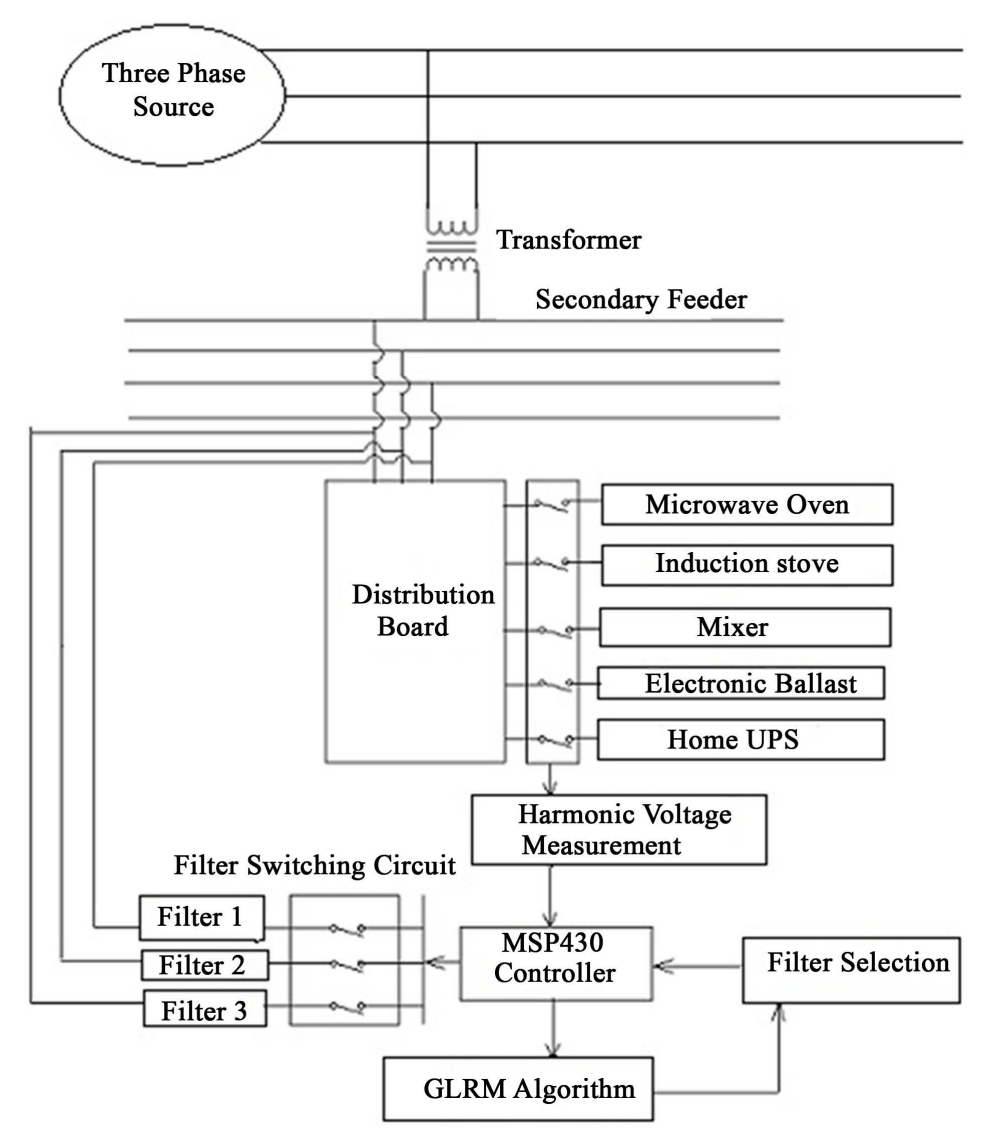

Figure 2. Block diagram of the proposed filter.

\section{Harmonic Order Detection with GLRM Algorithm}

From the practically measured data, different voltage level for different loads with the same harmonic order is analysed and the algorithm is formulated based on these analysis. For example for the different combination of load such as lamb-mixer, mixer-Microwave oven etc, the second harmonic voltages are tabulated as shown in Table 2. The tabulated values are used to formulate the algorithm based on linear regression.

The simple linear regression is with a set of " $n$ " variables, in accordance with a trial to fit the values to a straight line. A single variable can be chosen as the parameter to predict the outcome.

Let " $h$ " be the harmonic order and " $v$ " be the measured harmonic voltage. An attempt is made to relate both parameters by using simple linear regression method. Here V takes different harmonic voltages which is specified in a sample set. The sample set is as shown in Table 2.

The objective function of a straight line with a slope " $m$ " and $y$-intercept " $c$ " is as follows.

$$
Q=\sum_{i=1}^{n}\left(h_{i}-\hat{h}\right)^{2}=\sum_{i=1}^{n}\left(h_{i}-c-m v_{i}\right)^{2}
$$

Then, $Q$ will be minimized at the value of $m \& c$ for which

$$
\begin{gathered}
\frac{\partial Q}{\partial c}=0 \quad \& \quad \frac{\partial Q}{\partial m}=0 \\
\frac{\partial Q}{\partial c}=\sum_{i=1}^{n}-2\left(h_{i}-c-m v_{i}\right)=2\left(n c+m \sum_{i=1}^{n} v_{i}-\sum_{i=1}^{n} h_{i}\right)=0
\end{gathered}
$$

Dividing the above equation by 2 and solving for " $c$ "

$$
c=\bar{h}-m \bar{v}
$$


Table 2. Second order harmonic voltages for different loads.

\begin{tabular}{ccc}
\hline & SECOND ORDER HARMONICS & \\
\hline Load & VOLTAGE \\
\hline 1 & 0.01 \\
2 & 0.13 \\
4 & 0.28 \\
5 & 0.38 \\
\hline
\end{tabular}

This means that the y intercept " $c$ " is set in such a way that the line must go through the mean of $v \& h$. In other words this becomes the centre of data cloud. The second of minimizing the " $Q$ ” function is

$$
\frac{\partial Q}{\partial m}=\sum_{i=1}^{n}-2 v_{i}\left(h_{i}-c-m v_{i}\right)=0=\sum_{i=1}^{n}-2\left(v_{i} h_{i}-c v_{i}-m v_{i}^{2}\right)=0
$$

Substituting the value of " $c$ " in the above equation

$$
\begin{aligned}
& \sum_{i=1}^{n}\left(v_{i} h_{i}-v_{i} \bar{h}+m v_{i} \bar{v}-m v_{i}^{2}\right)=0 \\
& \sum_{i=1}^{n}\left(v_{i} h_{i}-v_{i} \bar{h}\right)-m \sum_{i=1}^{n}\left(v_{i}^{2}-v_{i} \bar{v}\right)=0
\end{aligned}
$$

Which yields,

$$
m=\frac{\sum_{i=1}^{n}\left(v_{i} h_{i}^{2}-v_{i} \bar{h}\right)}{\sum_{i=1}^{n}\left(v_{i}^{2}-v_{i} \bar{v}\right)}=\frac{\sum_{i=1}^{n}\left(v_{i} h_{i}\right)-n \bar{v} \bar{h}}{\sum_{i=1}^{n}\left(v_{i}^{2}\right)-n \bar{v}^{2}}
$$

It is known that

$$
\sum_{i=1}^{n}\left(\bar{v}^{2}-v_{i} \bar{v}\right)=0 \& \sum_{i=1}^{n}\left(\bar{v} \bar{h}-h_{i} \bar{v}\right)=0
$$

Therefore " $m$ " is written as

$$
\begin{gathered}
m=\frac{\sum_{i=1}^{n}\left(v_{i} h_{i}-v_{i} \bar{h}\right)+\sum_{i=1}^{n}\left(\bar{v} \bar{h}-h_{i} \bar{v}\right)}{\sum_{i=1}^{n}\left(v_{i}^{2}-v_{i} \bar{v}\right)+\sum_{i=1}^{n}\left(\bar{v}^{2}-v_{i} \bar{v}\right)} \\
m=\frac{\frac{1}{n} \sum_{i=1}^{n}\left(v_{i}-\bar{v}\right)\left(h_{i}-\bar{h}\right)}{\frac{1}{n} \sum_{i=1}^{n}\left(v_{i}-\bar{v}\right)^{2}}
\end{gathered}
$$

To modify the harmonic voltage equation a probability based convolution is addressed. The convolution involves harmonic voltage and order.

$$
m=\frac{\operatorname{Cov}(v, h)}{\operatorname{var}(v)}
$$

The variance clearly shows the error in the measurement of harmonic voltages for the same harmonic order.

$$
\sum v^{2}=s s_{v}=(n-1) \operatorname{var}(v)=\sum_{i=1}^{n}\left(v_{i}-\bar{v}^{2}\right)
$$




$$
\begin{gathered}
\sum v^{2}=\sum_{i=1}^{n}\left(v_{i}\right)^{2}-n \bar{v}^{2} \\
\sum h^{2}=s s_{h}=(n-1) \operatorname{var}(h)=\sum_{i=1}^{n}\left(h_{i}-\bar{h}\right)^{2} \\
\sum h^{2}=\sum_{i=1}^{n}\left(h_{i}\right)^{2}-n \bar{h}^{2} \\
\sum v h=s_{v h}=(n-1) \operatorname{Cov}(v, h)=\sum_{i=1}^{n}\left(v_{i}-\bar{v}\right)\left(h_{i}-\bar{h}\right) \\
\sum v h=\left(v_{i} h_{i}\right)-n \bar{v} \bar{h}
\end{gathered}
$$

The co-relation co-efficient can be calculated by using the following equation.

$$
r^{2}=\frac{\operatorname{Var}(\hat{h})}{\operatorname{Var}(h)}=\frac{m^{2} \operatorname{Var}(v)}{\operatorname{Var}(h)}=\frac{(\operatorname{Cov}(v, h))^{2}}{\operatorname{Var}(v) \operatorname{Var}(h)} \quad r^{2}=\frac{\operatorname{Var}(h)-\operatorname{Var}(h-\hat{h})}{\operatorname{Var}(h)}=\frac{s_{v h}^{2}}{s s_{v} s s_{h}}
$$

The correlation coefficient " $r$ ", the regression slope " $m$ " and the standard deviations of $v \& h$ is related as

$$
r=m \frac{s_{v}}{s_{h}}
$$

Also

$$
m=r \frac{s_{h}}{s_{v}}
$$

Here " $r$ " is the sample correlation coefficient. As this value nears to one the best result occurs. The genetic algorithm can be formulated by monitoring the value of " $r$ ". The formulated equation with a sample measured value of second harmonics for different load is as shown below.

$$
h=5.4979 v+1.2789
$$

The corresponding correlation coefficient is 0.96 .

As soon as the voltage information is received while using a particular combination of load, it is been fed to the equations of all the predominant harmonics and compares the value of " $r$ " for these harmonic orders. The selection of particular filter depends on the value of " $r$ ", in such a way that the particular harmonic order filter will be selected in accordance with the filter equation which yields maximum value of " $r$ ", since it satisfies best to the equation. The genetic algorithm plays a major role in selecting the parent equation for a particular measured value of voltage.

The selection of filter is based on genetic linear regression model algorithm. The GLRM algorithm takes the different " $r$ " value obtained from various regression equation. The regression equations form from different combination of loads and harmonic voltages. For example, if one load is in on condition, the harmonics generated from the load given as input for regression analysis to estimate the severity of the harmonics among the third, fifth and seventh levels. After identifying the severity, genetic algorithm suggest the priority of the filters whether to suppress third, fifth or seventh harmonics. The selection of harmonic order equations will keep on changing till an optimum solution of obtained. Once the best value of " $r$ " is obtained from an offspring harmonic order equation, the harmonic voltage is substituted in the equation and the particular harmonic order is found. According to the harmonic order the filters are switched by using a filter switching circuit. A filter switching circuit consists of switches which respond to the command of the controller to switch to the necessary filter.

\section{The Psuedo Code for GLRM Based Algorithm}

The linear regression method, a set of equations can be formed for different harmonic orders in terms of harmonic level voltages. The formulated equations consider as the members of population in GLRM algorithm. Genetic algorithm normally uses the principle of selection and evaluation to generate numerous solutions to a 
specified problem. In the algorithm, parents are selected according to the expected solution to get best performing offspring. Genetic Algorithm is one of the powerful tools to produce high quality solutions in any search space. In this tool the individuals are selected based on their fitness to perform a particular task. The paper explains of tuning a harmonic equation by the process of selection and evolution in such a way that the maximum value of regression correlation coefficient is obtained. By using the mutation process, the harmonic equation is fine tuned to achieve maximum value of " $r$ ".

The most common algorithm called Roulette Wheel selection is chosen to perform the selection of exact harmonic order equation. In Roulette wheel Selection the harmonic order equations are given a probability of being selected which is proportional to their fitness to perform the specified task which is getting an optimum harmonic equation with " $r$ " value close to one. The pseudo coding for the algorithm is as follows.

For all harmonic order equations in the population

Sum $+=$ fitness of this equation

End for

For all harmonic order equations of the population

Probability=Sum of probability + (fitness/sum)

Sum of probabilities $+=$ probability

End for

Loop until new population is full

Do this twice

Number $=$ random between 0 and 1

For all harmonic order equations

If number $>$ probability but less than the succeeding probability

Then particular harmonic order equation is selected.

End for

End

Create offspring

End loop

A block diagram on the above mentioned algorithm is given in Figure 3 for better understanding of the above pseudo code.

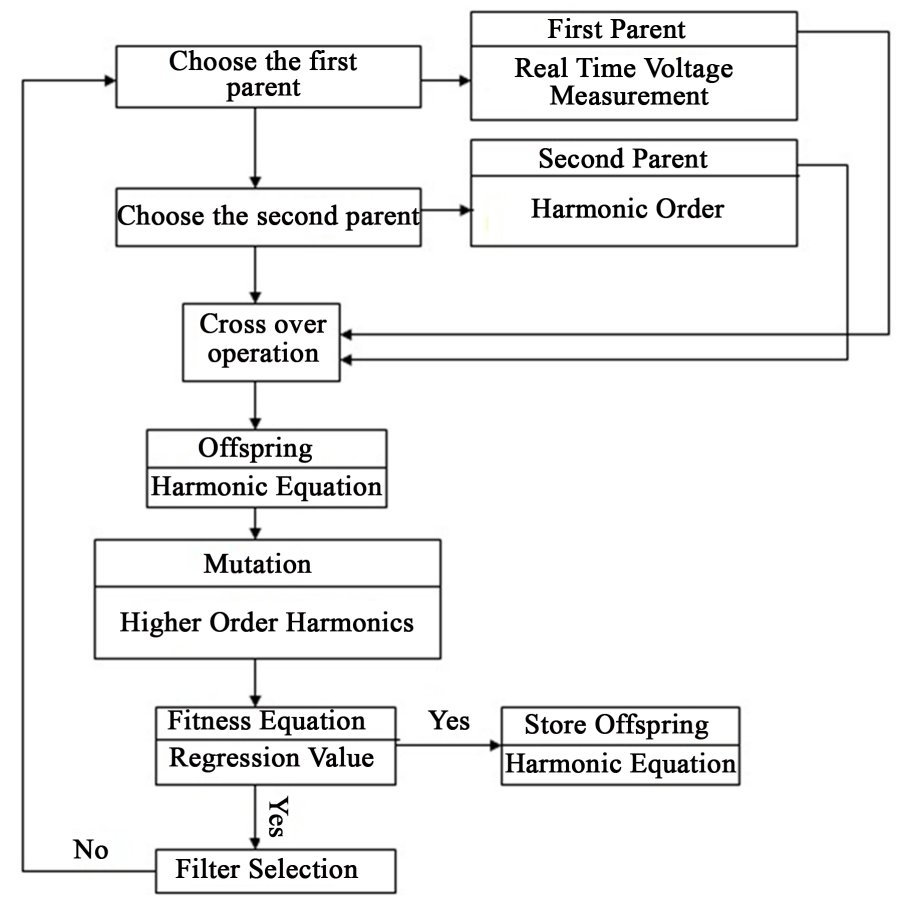

Figure 3. Block diagram representation of pseudo code. 
In real time implementation, the MSP430 controller is used for implementing the GLRM algorithm for evaluating the order of harmonics and voltage by means of FFT and harmonic voltage with regression equation. It is mainly a mixed signal microcontroller which is apt to analyse the signals from household appliances, since most of the signals are of mixed nature.

The following section shows the design aspects of the filter involved in the filter bank to eliminate the prominent harmonics in real time environment.

\section{Design Calculation of Filter for Different Harmonic Orders}

The design of filter bank is done based on the threshold values obtained from current drawn by the particular load combination considered which is tabulated in Table 3 . The filter bank contains three different filters for the elimination of $3^{\text {rd }}, 5^{\text {th }}$ and $7^{\text {th }}$ order harmonics. Each filter is a band pass filter whose output will be the particular harmonic order that is $3^{\text {rd }}$, $5^{\text {th }}$ or $7^{\text {th }}$ according to the predominant harmonic order in the current drawn by the particular load. For example Table 3 gives the value of harmonic currents in a real time situation when induction motor of $750 \mathrm{~W}$ and lamp load in running condition. When a lamp load is switched on, the fundamental component of current is increased to the scaled value 4505. Once motor is in on condition along with lamp and there is an increase in the threshold value to 4120 and as well as $5^{\text {th }}$ harmonics is been introduced with a value 32.17. The lamp load alone introduces a $3^{\text {rd }}$ order harmonics to the source current as observed by the value 17.96. Considering this analysis, the filter bank is designed to eliminate the particular dominant harmonics when a single load or a combination of different residential loads are switched-on. The first case in Table 3 is a stray voltage, which is denoted as load 1 . The second, third, and forth load are lamp load, lamp load with grinder and lamb acting with mixer respectively. A prototype of the set up which is designed and developed in a laboratory environment is shown in Figure 4.

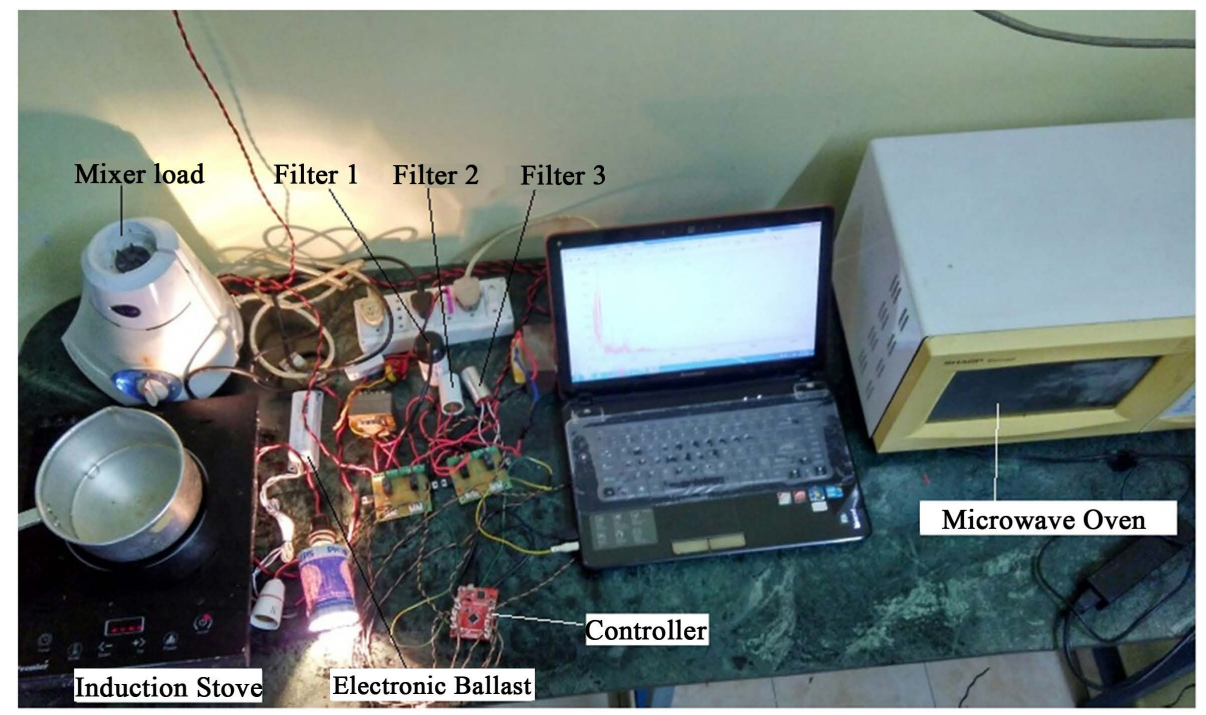

Figure 4. The prototype of the proposed filter.

Table 3. Filter coefficients for each dynamic load.

\begin{tabular}{|c|c|c|c|c|c|c|c|c|}
\hline \multirow{2}{*}{ Load } & \multicolumn{8}{|c|}{ Filter Coefficients (8) } \\
\hline & 1 & 2 & 3 & 4 & 5 & 6 & 7 & 8 \\
\hline 1 & 2. & 1.8 & 1.4 & 0.7 & 0 & 0.7 & 1.4 & 1.8 \\
\hline 2 & 4505 & 1.7 & 17.9 & 15.8 & 41.1 & 23.6 & 19.0 & 17 \\
\hline 3 & 4120 & 2.1 & 2.3 & 2.6 & 32.1 & 4.4 & 6.9 & 14 \\
\hline 4 & 4108 & 9.8 & 15.4 & 18.1 & 5.2 & 24.6 & 20.9 & 7.2 \\
\hline
\end{tabular}




\section{Third Order Harmonic Filter (Filter 1)}

A band pass filter is designed to acquire the third harmonic frequency from the current drawn by a combination of Microwave oven, Mixer, Induction stove and lamp. The mathematical equations used in designing a filter based on different harmonic order are given as follows. Fix the lower cut off $\left(f_{1}\right)$ and higher cut off frequency ( $\left.f_{2}\right)$ value according to the harmonic order and design the value of inductor and capacitor by using the following equations.

$$
\begin{gathered}
L_{13}=\frac{K}{\pi\left(f_{3 h}-f_{3 l}\right)} \\
C_{13}=\frac{f_{3 h}-f_{3 l}}{4 \pi K f_{3 h} f_{3 l}} \\
L_{23}=C_{13} K^{2} \\
C_{23}=\frac{L_{13}}{K^{2}}
\end{gathered}
$$

$f:$ Harmonic frequency

$L$ : Value of Inductor

$C$ : Value of Capacitor

K: Filter Constant in Ohms

A band pass T-filter will have a similar structure as shown in Figure 5.

Similarly 5th harmonic and 7th harmonic filters can be designed by implementing the above mentioned equations with the required frequencies.

Table 4 shows the designed value of inductor for a particular value of capacitor and a harmonic order.

In the following section the current drawn by home appliances has been analysed and the filtered output is analysed to find the effectiveness of the filter.

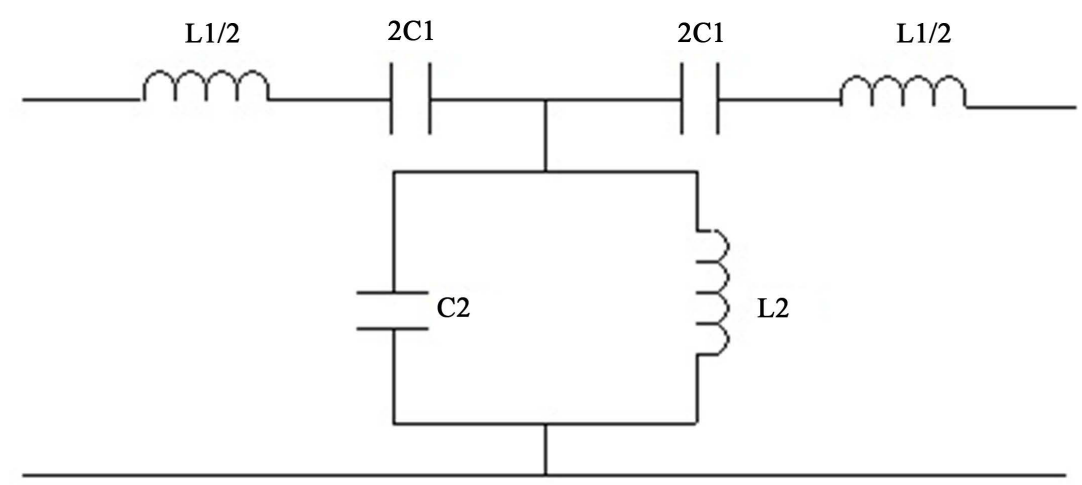

Figure 5. Circuit diagram of a band pass filter.

Table 4. Band pass filter parameters.

\begin{tabular}{ccccc}
\hline \multirow{2}{*}{ Sl.No } & \multicolumn{2}{c}{ SOURCE $: \mathbf{2 3 0 V}, \mathbf{5 0 H z}$} & \\
\cline { 2 - 5 } & Component & $\mathbf{3}^{\text {rd }}$ Harmonic & $\mathbf{5}^{\text {th }}$ Harmonic & $\mathbf{7}^{\text {th }}$ Harmonic \\
\hline 1. & Filter Constant $\mathrm{K}(\Omega)$ & 500 & 500 & 500 \\
2. & $\mathrm{C}_{1}(\mu \mathrm{F})$ & 2.06 & 0.419 & 0.18 \\
3. & $\mathrm{C}_{2}(\mu \mathrm{F})$ & 6.36 & 6.36 & 6.36 \\
4. & $\mathrm{~L}_{1}(\mathrm{mH})$ & 1590 & 1590 & 1590 \\
5. & $\mathrm{~L}_{2}(\mathrm{mH})$ & 516 & 104 & 0.045 \\
\hline
\end{tabular}




\section{Results \& Discussion}

Figure 5 shows a scaled value of current drawn by a combination of Microwave oven, induction stove, mixer and a lamb load. Due to the presence of $3^{\text {rd }}, 4^{\text {th }}$ and $5^{\text {th }}$ harmonics, the current drawn from the supply is highly distorted. The total harmonic distortion (THD) is calculated to 63.67\% from the graph shown in Figure 6.

An FFT spectrum of the nonlinear current is shown in Figure 6. From the FFT spectrum analysis it is clear that the odd harmonics are prominent in the load current. The third harmonic is having a value of 0.66 and the fifth harmonic a value of 0.62 as shown in Figure 7. The third harmonic frequency and fifth harmonic magnitude seems to be one third of the magnitude of the fundamental supply current, which will distort the ideal sinusoidal supply to a large extent, resulting a THD of $63.67 \%$. Figure 7 shows that at $150.06 \mathrm{~Hz}$ the scaled value of harmonic current magnitude is 0.66 and similarly at $249.99 \mathrm{~Hz}$ the value is 0.62 . The third harmonic is generated mainly due the electric motor used in the mixer and the main source of fifth harmonics is the electronic ballast used in the lamb load. Figure 8 shows the bar diagram of the above analysis, plotting the magnitude of harmonic current against the harmonic order.

A third order harmonic will lead to a zero sequence current which will in turn cause neutral conductor heating. A fifth orders harmonic will cause pulsating torque in motors and which is an adverse effect as far as home appliances like mixer and grinders are concerned. This pulsating torques will decrease the lifetime of many residential types of equipment.

When a combination of load which shows predominant third harmonic frequency is in operation, then the filter1 will act from the filter bank. In the next second a combination of house hold appliance which insert a $7^{\text {th }}$ harmonic is connected to the supply system, then filter 3 will be acting with an immediate switch over.

The particular order filter selected from the filter bank is connected at the point of common coupling between the source and the load. Figure 9 shows the compensated source current after connecting the filter. The total

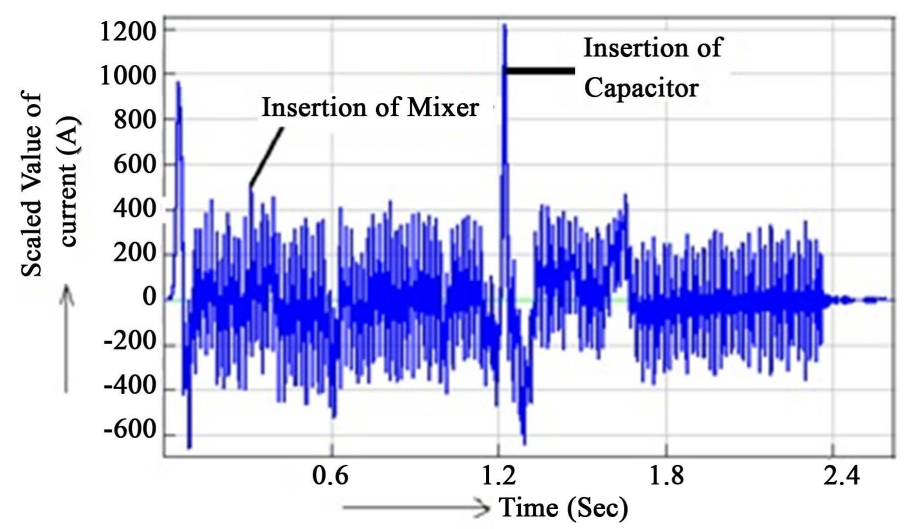

Figure 6. Nonlinear current drawn from combination of microwave, mixer, induction stove and lamp.

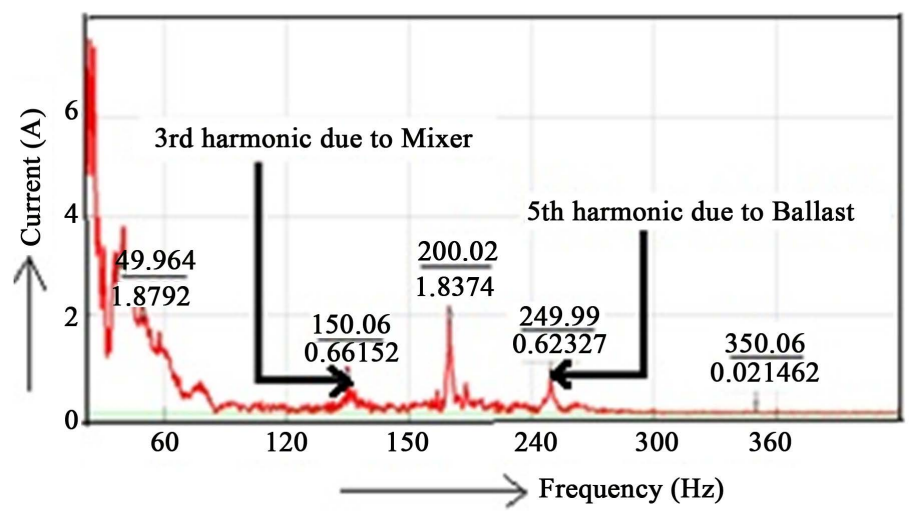

Figure 7. Harmonic order and current magnitude of the combinational load-microwave oven, mixer, induction stove and ballast. 


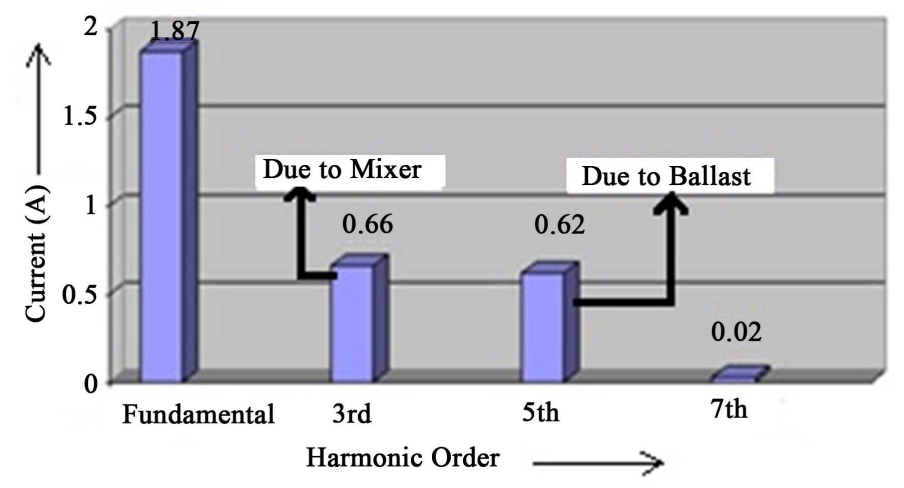

Figure 8. Bar diagram of the combinational load of microwave oven, mixer, induction stove and ballast.

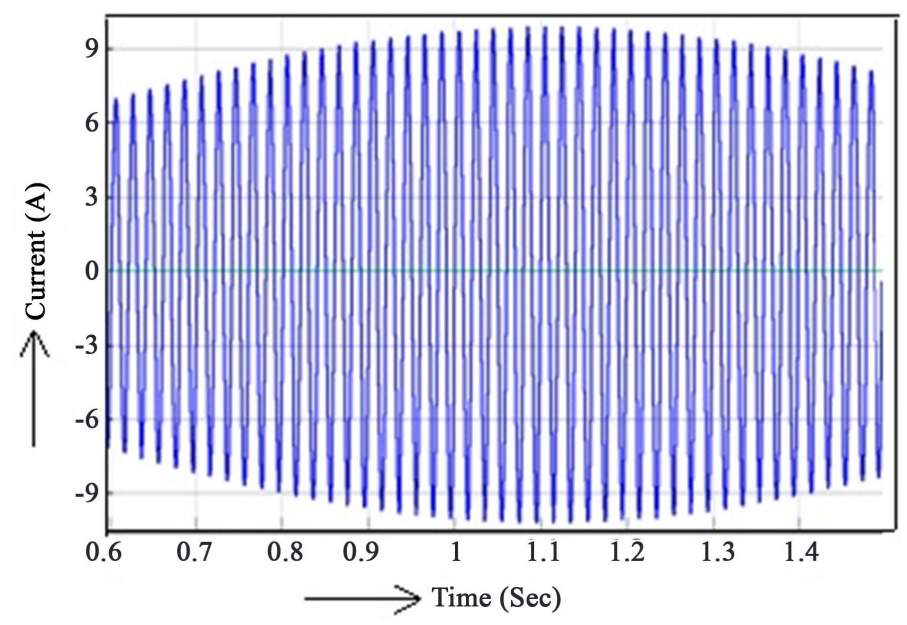

Figure 9. Current drawn from combinational load of microwave oven, mixer, induction stove and ballast after compensation.

harmonic distortion is now reduced to $3.68 \%$ from $63.67 \%$. It shows $60 \%$ reduction in THD, which shows the effectiveness of the filter.

Figure 9 shows the compensated source current from current sensor after the filter is been acted. It can be observed that the wave form is almost free of distortion.

The FFT spectrum after compensation with GLRM algorithm is shown in Figure 10 gives the effectiveness of filtering with the proposed system.

Figure 10 shows that the third order harmonics is reduced to $1.052 \mathrm{e}-008$, the fifth harmonic and the seventh harmonic component reduced to $1.837 \mathrm{e}-009,2.214 \mathrm{e}-009$ respectively and hence the total harmonic distortion is reduced to 3.68\%.The bar chart shown in Figure 11 helps to understand the harmonic order more clear. From the spectrum it is clear that the third harmonic component is considerably reduced and now it will not have much impact on the source current.

The algorithm seems to be effective from the analysis of reduction in current consumption when filter is connected. The current consumed by a microwave oven of 600 watts, is $2.6 \mathrm{~A} /$ hour without a filter while the current consumption seems to be reduced by almost $39 \%$ with the filter. The current consumed by the load after connecting the filter is $1.59 \mathrm{~A}$. Similarly, for 300 watts mixer current consumes around 1.4 A without a filter, while it consumes $0.854 \mathrm{~A}$ with a filter. From these data it is proved that the filter is able to save an amount of power $30 \%$ when various loads are switched to the power system. A mixer without a filter consumes around 0.2576 $\mathrm{kW}$ in an hour. The same mixer draws $0.854 \mathrm{~A}$ with filter which means the power consumption is reduced to $0.1571 \mathrm{~kW}$ in an hour. This shows that there will be a $15 \%$ reduction in the electricity bill on a monthly basis.

Under an ideal condition of supply system a microwave oven will consume around 1.35 A per hour. The same load under normal supply system draws 2.6 A per hour due to the presence of different harmonics. By imple- 


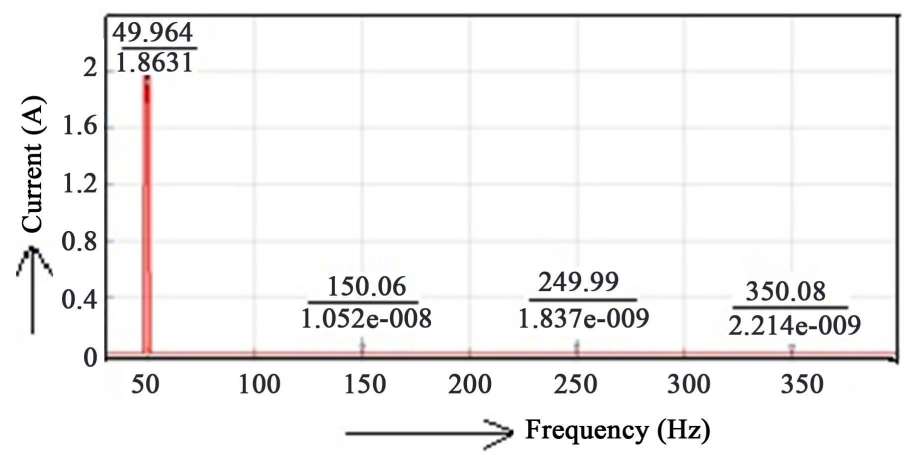

Figure 10. Harmonic order and current magnitude of the combinational load of microwave oven, mixer, induction stove and ballast after compensation.

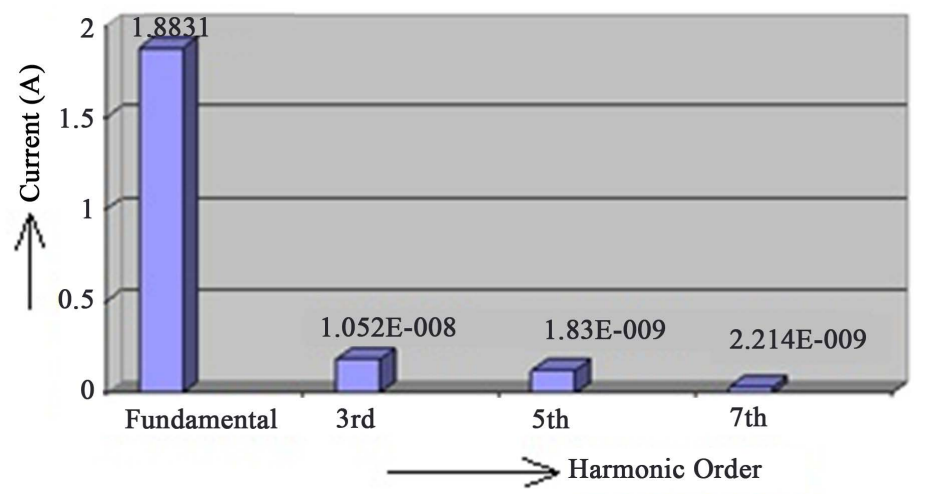

Figure 11. Bar diagram of the combinational load after compensation.

menting the proposed filter system, the current drawn by the same load is reduced to 1.59 A per hour, showing that the current consumption is reduced by $1.01 \mathrm{~A}$. Comparing with the ideal condition the overall system efficiency is improved to $85 \%$ from about $51.6 \%$.

\section{Conclusion}

Power quality plays a major role in saving the life of equipments as well as in saving the power, hence the mitigation of harmonics is of at most importance. The proposed system is able to detect and reduce the harmonics with different load running conditions and duration. The GLRM algorithm works well with detection of harmonics and in the optimal selection of filter for the corresponding harmonic order. In this paper a combinational load of Microwave oven, induction stove, mixer, a lamb is connected to the supply system and the harmonic analysis for those connected loads is performed. The predominant harmonic order is identified and mitigated by using filter bank in combination with the proposed algorithm. The total harmonic distortion after filtering is observed to be $3.68 \%$ which is well within IEEE standards. The filter brings a power quality of an average of $85 \%$ and reduction in billing of about $15 \%$. Still the power quality can be increased when the obtained harmonic order and harmonic voltage for identifying the faults in the individual domestic loads. The same algorithm can be modified to identify the faults in the machines with the knowledge of the harmonic order.

\section{Acknowledgements}

The authors are deeply acknowledging Dr. N. R. Shanker, Manager, R \& D wing, Microne Industries for partial financial support.

\section{References}

[1] Tuyen, N.D. and Fujita, G. (2015) PV-Active Power Filter Combination Supplies Power to Nonlinear Load and Compensates Utility Current. IEEE Power and Energy Technology Systems Journal, 2, 32-42. 
[2] Bagheri, P., Xu, W. and Ding, T. (2015) A Distributed Filtering Scheme to Mitigate Harmonics in Residential Distribution Systems. IEEE Transactions on Power Delivery, 31, 648-656.

[3] Rq, H. and Hyho, H. (2012) Evaluation the Long-Term Impact of a Continuously Increasing Harmonic Load Demand on Feeder Level Voltage Distortion. IEEE, 8, 1-8.

[4] Bagheri, P. and Xu, W. (2014) A Technique to Mitigate Zero-Sequence Harmonics in Power Distribution Systems. IEEE Transactions on Power Delivery, 29, 215-223. http://dx.doi.org/10.1109/tpwrd.2013.2291866

[5] Pinceti, P. and Prando, D. (2015) Sensitivity of Parallel Harmonic Filters to Parameters Variations. International Journal of Electrical Power \& Energy Systems, 68, 26-32. http://dx.doi.org/10.1016/j.ijepes.2014.12.030

[6] Schofield, N. (2015) Shunt Active Power Filtering for Smart Appliances. Proceeding of the IEEE 28th Canadian Conference on Electrical and Computer Engineering, Halifax, 3-6 May 2015, 466-470.

[7] Todeschini, G., Mueller, D.R. and Morris, G.Y. (2013) Telephone Interference Caused by Harmonics in Distribution Systems : Analysis and Simulations. IEEE Power \& Energy Society General Meeting, Vancouver, 21-25 July 2013, 1-5. http://dx.doi.org/10.1109/pesmg.2013.6672175

[8] Bokhari, A., Alkan, A., Dogan, R., Diaz-Aguilo, M., de Leon, F., Czarkowski, D., Zabar, Z., Birenbaum, L., Noel, A. and Uosef, R.E. (2014) Experimental Determination of the ZIP Coefficients for Modern Residential, Commercial, and Industrial Loads. IEEE Transactions on Power Delivery, 29, 1372-1381. http://dx.doi.org/10.1109/TPWRD.2013.2285096

[9] Anton, D., Su, K.N. and Kwan, K.Y. (2015) Future Drives of Home Appliances: Elimination of the Electrolytic DC-Link Capacitor in Electrical Drives for Home Appliances. IEEE Industrial Electronics Magazine, 9, 10-18.

[10] Arco, S.D., Piegari, L. and Tricoli, P. (2014) Harmonic Compensation with Active Front-End Converters Based Only on Grid Voltage Measurements. 3rd Renewable Power Generation Conference (RPG 2014), Naples, 24-25 September 2014, 1-6.

[11] Fujita, G., Dinh, N.D., Funabashi, T. and Tuyen, N.D. (2015) Adaptive Notch Filter Solution under Unbalanced and/or Distorted Point of Common Coupling Voltage for Three-Phase Four-Wire Shunt Active Power Filter with Sinusoidal Utility Current Strategy. IET Generation, Transmission \& Distribution, 9, 1580-1596. http://dx.doi.org/10.1049/iet-gtd.2014.1017

[12] Liu, Y., Wang, X. and Liu, Y. (2015) Asynchronous Harmonic Analysis Based on Out-of-Sequence Measurement for Large-Scale Residential Power Network. IEEE International Instrumentation and Measurement Technology Conference (I2MTC) Proceedings, Pisa, 11-14 May 2015, 1693-1698.

[13] Yahyaie, F. and Lehn, P.W. (2015) Using Frequency Coupling Matrix Techniques for Analysis of Harmonic Interactions. IEEE Transactions on Power Delivery, 31, 112-121.

[14] Wang, X., Blaabjerg, F. and Loh, P.C. (2015) Virtual RC Damping of LCL-Filtered Voltage Source Harmonic Compensation. IEEE Transactions on Power Electronics, 30, 4726-4737.

[15] Fan, L., Yuvarajan, S. and Kavasseri, R. (2010) Harmonic Analysis of a DFIG for a Wind Energy Conversion System, IEEE Transactions on Energy Conversion, 25, 181-190.

[16] Wei, Y. and Wang, Y. (2015) Design of Low Complexity Adjustable Filter Bank for Personalized Hearing Aid Solutions. IEEE/ACM Transactions on Audio, Speech, and Language Processing, 23, 923-931. http://dx.doi.org/10.1109/taslp.2015.2409774

[17] Allenbaugh, M.L., Dionise, T.J. and Natali, T.J. (2013) Harmonic Analysis and Filter Bank Design for a New Rectifier for a Cold Roll Mill. IEEE Transactions on Industry Applications, 49, 1161-1170. http://dx.doi.org/10.1109/tia.2013.2252874

[18] Boukhobza, A., Bounoua, A., Ahmed, A.T. and Taleb, N. (2009) A Filter Banks Design Using a Multiobjecive Genetic Algorithm for an Image Coding Scheme. 16th IEEE International Conference on Image Processing (ICIP), Cairo, 7-10 November 2009, 1933-1936. http://dx.doi.org/10.1109/icip.2009.5413533

[19] Jin, S., Diao, R., Quek, C., Member, S. and Shen, Q. (2014) Backward Fuzzy Rule Interpolation. IEEE Transactions on Fuzzy Systems, 22, 1682-1698. http://dx.doi.org/10.1109/tfuzz.2014.2303474

[20] Hao, J., Piechocki, R.J., Kaleshi, D., Chin, W.H. and Fan, Z. (2015) Defense Mechanisms in Smart Grids. IEEE Transactions on Industrial Informatics, 11, 1198-1209.

[21] Gmyrek, Z., Boglietti, A. and Cavagnino, A. (2010) Estimation of Iron Losses in Induction Motors : Calculation Method, Results, and Analysis. IEEE Transactions on Industrial Electronics, 57, 161-171. 


\section{Submit or recommend next manuscript to SCIRP and we will provide best service for you:}

Accepting pre-submission inquiries through Email, Facebook, Linkedin, Twitter, etc A wide selection of journals (inclusive of 9 subjects, more than 200 journals)

Providing a 24-hour high-quality service

User-friendly online submission system

Fair and swift peer-review system

Efficient typesetting and proofreading procedure

Display of the result of downloads and visits, as well as the number of cited articles

Maximum dissemination of your research work

Submit your manuscript at: http://papersubmission.scirp.org/ 